\title{
Evaluation of the Microbiological Quality of Drinking Water in the District of Bragança (Northwest Portugal) throughout a Ten-Year Period (1996-2005), during the Implementation of the 1998/83 EC Directive
}

\author{
A. Nogueira Public Health Laboratory of Bragança and University of Aveiro \\ M. Cardoso Public Health Laboratory of Bragança \\ I. Delgadillo University of Aveiro \\ A. Almeida* University of Aveiro
}

[[Author: In Table Head for Table 2, can the "b" in

"Parametric value b" and "a" in "RMV a" and "AMV a" be deleted? If not, please provide explanation of the letters to be added to a table footnote. Also, Figure 2 legend had no definition for $C$. I changed " $B$ " to " $C$ " and combined " $A$ " and " $B$ " in the legend. Please check edit and change as needed. ]]

The microbiological quality of drinking waters was evaluated in northwestern Portugal between 1996 and 2005, according to the guidelines of European Directives of 1980 and 1998. Out of the 21,630 microbiological analyses done, the percentage of treated and nontreated waters analyzed were similar, but the fraction of conforming samples were higher for treated (74.2\%) than for nontreated $(37.8 \%)$ water. The microbiological quality of potable water improved throughout the study period, particularly in the last $2 \mathrm{yr}$, when drinkable water reached $70 \%$. The increase during the last $2 \mathrm{yr}$ is a result of at least two different causes: an increase in the use of treated waters and the change in the legislation (1998/83 EC Directive). Although the number of treated waters has increased, the nonconforming treated water is still very high $(25 \%)$ even when evaluated under the 1998/83 EC Directive.
Copyright $\odot 2010$ by the American Society of Agronomy, Crop Science Society of America, and Soil Science Society of America. All rights reserved. No part of this periodical may be reproduced or transmitted in any form or by any means, electronic or mechanical, including photocopying, recording, or any information storage and retrieval system, without permission in writing from the publisher.

Published in J. Environ. Qual. 39:1-8 (2010).

doi:10.2134/jeq2009.0034

Published online INSERT DATE HERE

Received 26 Jan. 2009.

${ }^{*}$ Corresponding author (aalmeida@ua.pt).

(c) ASA, CSSA, SSSA

677 S. Segoe Rd., Madison, WI 53711 USA
Cafe water for human consumption is defined by the World $\checkmark$ Health Organization (WHO) as water that does not cause a significant hazard to human health during its consumption (World Health Organization, 2004a). Persistence and development of microorganisms in waters are major threats to human health and are affected by a complex variety of physical, chemical, and biological factors (Anderson et al., 2005).

A real knowledge on the quality of water permits the application of better treatments and strategies to obtain waters fit for consumption. This can avoid a great variety of drinking-water related diseases (Barrel et al., 2000; Strauss et al., 2001; Hellard et al., 2001; Amaral et al., 2003; Nogueira et al., 2003; Mendes and Oliveira, 2004; World Health Organization, 2004a; Chiller et al., 2006) and public health problems. Governments from all over the world should seek to establish regulations to ensure good water quality and, consequently, to decrease the number of diseases associated with water consumption. In Europe, these standards are defined by the European Union and all member countries transpose them into national law. The current European Drinking Water Directive is $1998 / 83 / \mathrm{EC}$, corresponding to the Decree 243/2001 (2001) in Portugal. Compared with the previous European Drinking Water Directive of 1980 (Directive 80/778/EEC, Decree 74/1990 [1990] and Decree 236/1998 [1998] in Portugal), the new legislation introduced important changes in the microbiological control of drinking water. The number of microbiological parameters decreased slightly and some fecal indicators were replaced by surrogate ones (Decree 74/1990, 1990; Decree 236/1998, 1998; Decree 243/2001, 2001).

In the new European Directive, the determination of fecal coliforms was replaced by the determination of Escherichia coli, and that of sulfite-reducing clostridia spores (SRCS) was replaced by the determination of Clostridium perfringens (including spores).

A. Nogueira and M. Cardoso, Public Health Laboratory of Bragança, Rua D. Afonso V, 5300-146 Bragança, Portugal. A. Nogueira and I. Delgadillo, Dep. of Chemistry, Univ. of Aveiro, 3810-193 Aveiro, Portugal. A. Almeida, CESAM and Dep. of Biology, Univ. of Aveiro, 3810-193 Aveiro, Portugal.

Abbreviations: AMV, admissible maximum value; $\mathrm{BPHL}$, Bragança's Public Health Laboratory; PV, parametric value; RMV, recommendable maximum value; SRCS, sulfitereducing clostridia spores 
The new standard for $C$. perfringens differs from the old directive standard of sulfite-reducing clostridia spores in that the organism must be absent in $100 \mathrm{~mL}$ rather than in $20 \mathrm{~mL}$. With this new legislation total bacterial counting at $37^{\circ} \mathrm{C}$ was also suspended. The enterococci group was the sole fecal indicator that was maintained in the new Directive. The reference method used to detect coliforms and E. coli in nontreated waters, according to 1988 Directive, is now membrane filtration, instead of the Most Probable Number method. Althought this legislation also brought some changes regarding sampling point definition and water sampling frequency, these have not been implemented in the District of Bragança, Northern Portugal. So, the differences in water sample classification are due solely to the use of different criteria of evaluating and to a different proportion of treated waters, and is not related to a different sampling approach.

One of the main causes associated with bad water quality is the lack of basic sanitation (Mendes and Oliveira, 2004). In rural areas, such as some locations in the District of Bragança, there are no sewer treatment systems. Water treatment and disinfection by chlorine has an unquestionable importance in the supply of safe drinking-water (World Health Organization, 2004a). Although chlorine disinfection may lead to the formation of disinfection by-products (DBPs) such as trihalomethanes (THMs), which may present health risks, these risks are low when compared with those associated with an inadequate disinfection (Nieuwenhuijsen et al., 1999; Tominaga and Midio, 1999; Bove et al., 2002; World Health Organization, 2004a,b). Water disinfection, when properly used, should be a primary tool for Public Health protection around the world (World Health Organization, 2004a; Chiller et al., 2006).

The objective of this study was to assess the microbiological quality of drinking water during the implementation of the 1998/83/EC European Directive to evaluate (i) whether a new suite of indicators are effective in ensuring screening of potential microbial contaminants in water supply, and (ii) whether treatment of water supply is improving with regard to potential microbial contaminants.

\section{Materials and Methods}

\section{Sampling Site and Study Period}

The District of Bragança is located in northwest Portugal (Fig. 1). The public system of drinking water treatment varies within the municipalities. Whereas in the municipalities' center, water is treated in Water Treatment Stations (around 8\% of the analyzed waters), in rural areas water is usually only disinfected with chlorine (around $40 \%$ of the analyzed waters). In some rural areas, nontreated waters are also distributed in the public network without disinfection. Sometimes the same network is supplied with several water sources, especially during droughts due to the diminished water streams or increased consumption. In this study the term treated water applies to waters that are actually treated in Water Treatment Stations and also to

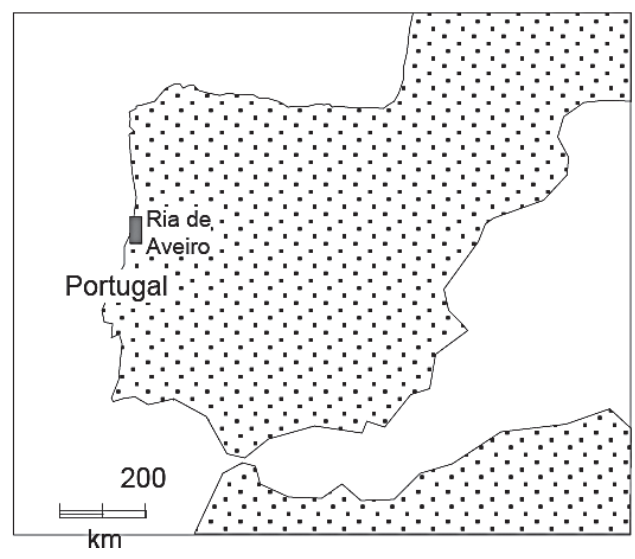

Fig. 1. Map of Portugal showing the District of Bragança.

waters that are only chlorinated. The term nontreated water applies to water without any treatment.

We analyzed the microbiological quality of the drinking water of the District of Bragança using Bragança's Public Health Laboratory (BPHL).The microbiologic data of the BPHL refers to the 1996-2005 period (21,630 samples). During the study period some interruptions to the microbiological analysis occurred, making data unavailable for some dates. Data were initially organized and inputted into a database using Microsoft Excel and statistically treated with the SPSS version 13.0 program.

\section{Study Parameters}

Microbiological parameters studied in this work were based on the ruling legislation and included total and fecal coliforms, enterococci, sulfite-reducing clostridia spores, $C$. perfringens, E. coli, and total bacterial counts at 37 and $22^{\circ} \mathrm{C}$. To assess the microbiological quality of the drinking water, the reference methods used followed the legislation practiced at the date of the analysis (Decree 74/1990, 1990; Decree 236/1998, 1998; Decree 243/2001, 2001).

\section{Quantification Methods}

Total Coliforms, Fecal Coliforms, and Escherichia coli: Most Probable Number Technique

Until February 2003 for the nontreated waters, the most probable number (MPN) technique was used for both total and fecal coliforms. MacConkey Broth (Merck, Darmstadt, Germany) and EC broth (Merck, Darmstadt, Germany) were used in presumptive and confirmatory tests, respectively (APHA, 1995).

\section{Membrane Filtration Method}

Until February of 2003 for the treated water and after February of 2003 for the both treated and nontreated waters, total and fecal coliforms were analyzed by the filter-membrane membrane method, using lauryl tryptose broth (Oxoid, Basingstoke, England) as presumptive medium and brilliant green lactose bile broth (Oxoid, Basingstoke, England) and saline 
tryptone broth (Oxoid, Basingstoke, England) as confirmatory media (ISO, 2000a).

\section{Heterotrophic Plate Counts}

Heteroptrophic plate counts were determined by pour-plate method, using nutrient agar medium (Oxoid, Basingstoke, England). Two sets of plates were prepared; one set was incubated at $37^{\circ} \mathrm{C}$ and another set at $22^{\circ} \mathrm{C}$ (ISO, 1999).

\section{Spores of Sulfite-reducing Clostridia}

For the enumeration of the spores of sulfite-reducing clostridia, heated water replicates were analyzed by the filter-membrane method, using agar sulfito tryptose medium (Oxoid, Basingstoke, England) (ISO, 1986a).

\section{Clostridium perfringens}

Clostridium perfringens was analyzed by filter-membrane method, using tryptose-sulfite-cycloserine medium (Oxoid, Basingstoke, England) as presumptive medium and lactose sulfite broth (Biogerm, Maia, Portugal), and tamponated nitrate medium (Biogerm, Maia, Portugal) as confirmatory media (ISO, 1986b). Gram stain, motility, stormy fermentation, gelatin liquefaction were also done as confirmatory tests (ISO, 1986b).

\section{Enterococci}

The enumeration of enterococci was done by filter-membrane method, using Preheated Slanetz and Bartley medium (Oxoid, Basingstoke, England) and preheated eEsculin-azide agar (Merck, Darmstadt, Germany) as confirmatory medium (ISO, 2000b).

\section{Legislation Relevant to the Study}

The microbiological classification of the water for human consumption in this study was based on the Government Decree 74/1990 (1990), transposed from the European Directive of 1980. Although this was revoked by Government Decree $236 / 1998$ (1998), the parameters were maintained. In these decrees the term potable is used when all values are less than the recommendable maximum value (RMV). The term improper is used when at least one value is greater than the admissible maximum value (AMV). The term $>R M V$ is used when no value is superior to the AMV but when the number of total counts, at 22 and $37^{\circ} \mathrm{C}$, exceed the RMV. Since 2004 in Portugal (on the 24 May 2004 in the BPHL), with the approval of Government Decree 243/2001 (2001), transposed from the Directive 1998/83/EC, the terminology potable, improper, and superior to the $R M V$ were revoked by the terms conform and nonconform. The designation conform is used when no value is greater than the parametric value (PV). Parametric value points to a specified value, or maximum or minimum concentration for a property, element, organism, or substance. The designation nonconform is used when at least one value is over the PV (Decree 74/1990, 1990; Decree 236/1998, 1998; Decree 243/2001, 2001).

\section{Results}

\section{Microbiologic Classification of Drinking Water according to the Ruling Legislation}

The analysis of water supply samples in the District of Bragança, resulted in 8225 (38.03\%) classified as improper, 7169 (33.14\%) potable, 2056 (9.51\%) with > RMV, 2770 (12.81\%) as conforming and 1410 (6.25\%) as nonconforming. Considering only the Decree 243/2001 (2001) for the study period, conforming water samples would represent $55.45 \%$. During this period, half of the microbiological analyses were made to treated waters, of which two-thirds were classified as conforming, whereas only one-third of the nontreated waters was classified as conforming (Table 1).

Using the rules anterior to the implementation of the Decree $243 / 2001$ (2001), the percentage of potable waters would be lower $(41.08 \%$ against $47.13 \%$ as improper and $11.78 \%$ as $>\mathrm{RMV})$ than following the new directive $(66.27 \%$ against $33.73 \%$ as nonconform).

Of the microorganisms studied, the concentration of total bacterial counts at $37^{\circ} \mathrm{C}$ was the parameter that most often exceeded the RMV (10 CFU/mL). About $46.7 \%$ of the water samples analyzed exceeded the RMV (Table 2). If total bacterial counts at $37^{\circ} \mathrm{C}$ were ignored, considering only the heterotrophic plate counts at $22^{\circ} \mathrm{C}$, as in the $1998 / 83$ EC Directive, only $27.8 \%$ of the samples exceeded the RMV (Table 2 ). The concentration of total coliforms was the second parameter that most often exceeded the PV (0 CFU/mL). Total coliforms were detected in $35 \%$ of the water samples analyzed. The parameter which less often exceeded the PV was $C$. perfringens which only went over the legislated limit $(0 \mathrm{CFU} / \mathrm{mL})$ in $2 \%$ of the water samples analyzed (Table 2).

\section{Microbiological Quality of Drinking Water during the Study Period}

Microbiological quality of drinking water in the District of Bragança improved throughout the study period (Fig. 2A). During the first $3 \mathrm{yr}$ following legislation, the percentage of nonconforming water varied between 49.8 and 45.0\%. In 1999 and 2000 , the fraction of nonconforming waters decreased slowly to $45.2 \%$. During the next $3 \mathrm{yr}$, the percentage of nonconforming water once more reached values above $50 \%$. In the last $2 \mathrm{yr}$, the fraction of nonconforming waters decreased greatly

Table 1. Microbiological classification of water for human consumption in the District of Bragança, between 1996 and 2005, according to Government Decree 243/2001 (2001).

\begin{tabular}{llccc}
\hline & & \multicolumn{2}{c}{ Water type } & \multirow{2}{*}{ Total } \\
\cline { 3 - 4 } & & Treated & Nontreated & \\
\hline Conform & No. of samples & 7,782 & 4,213 & 11,995 \\
& Percentage & $74.2 \%$ & $37.8 \%$ & $55.45 \%$ \\
\multirow{2}{*}{ Nonconform } & No. of samples & 2,708 & 6,927 & 9,635 \\
\cline { 3 - 4 } Total & Percentage & $25.8 \%$ & $62.2 \%$ & $44.55 \%$ \\
& No. of samples & 10,490 & 11,140 & 21,630 \\
& Percentage & $48.5 \%$ & $51.5 \%$ & $100.0 \%$ \\
\hline
\end{tabular}


Table 2. Microbiological parameters on drinking water in the District of Bragança between 1996 and 2005.

\begin{tabular}{|c|c|c|c|c|}
\hline Parameter & No. of analysis & Parametric value $b$ & $\begin{array}{l}\text { RMV a } \\
\text { AMV a† }\end{array}$ & $\begin{array}{c}\text { No. }>\text { parametric value or RMV } \\
\text { or }>\text { AMV }\end{array}$ \\
\hline Total germs at $37^{\circ} \mathrm{C}$ & 17,450 & - & $10 \mathrm{CFU} / \mathrm{mL}$ (RMV) & $8144,46.7 \%$ \\
\hline Total germs at $22^{\circ} \mathrm{C}$ & 16,408 & - & 100 CFU/mL (RMV) & $4555,27.8 \%$ \\
\hline Total coliforms & 21,630 & $0 \mathrm{CFU} / 100 \mathrm{~mL}$ & - & $7571,35 \%$ \\
\hline Fecal coliforms & 21,630 & $0 \mathrm{CFU} / 100 \mathrm{~mL}$ & - & $5136,23.7 \%$ \\
\hline Enterococci & 21,630 & 0 UFC/100 mL & - & $5386,24.9 \%$ \\
\hline Clostridia spores & 17,450 & - & $<1 / 20 \mathrm{~mL}$ (AMV) & $3118,17.9 \%$ \\
\hline Clostridium perfringens & 4,180 & $0 \mathrm{CFU} / 100 \mathrm{~mL}$ & - & $80,1.9 \%$ \\
\hline Escherichia coli & 5,366 & $0 \mathrm{CFU} / 100 \mathrm{~mL}$ & - & $583,10.9 \%$ \\
\hline
\end{tabular}

† RMV, recommendable maximum value; $A M V$, admissible maximum value.

for both treated (around 60\%) and nontreated (around 21\%) waters (average 30\%) (Fig. 2A). When water quality is evaluated considering only the enterococci group, the pattern of variation of the evolution of nonconform waters is similar to that when all parameters are considered, but the decrease in the last period is less evident (Fig. 2B).

The percentage of treated waters also increased throughout the study (Fig. 2C). During the first $2 \mathrm{yr}$, the percentage of treated water was around 20\%; between 1998 and 2001 it increased to 33 to $45 \%$ and in 2002 it increased above the percentage of nontreated waters, reaching $53.5 \%$. During the following years the fraction of treated waters was always higher than nontreated waters, reaching values of 70 and $73 \%$ in 2004 and 2005, respectively (Fig. 2C). During the study we observed that bacterial concentration in nontreated waters was always greater than in treated waters (Fig. 3), occasionally much greater.

In contrast, the concentration of the various bacterial groups, in general, did not vary much during the study period. The SRCS and the total coliforms were the parameters with a high range of variation during the study period. The ratio between the highest and the lowest values was 18 and 12 for SRCS, respectively, for treated and nontreated waters, and 32 and 7 for total coliforms. For the other parameters, the ratio between the highest and the lowest values was, on average, 4 and 3 for treated and nontreated waters. Nevertheless, peaks in bacterial concentration were observed in 1999 and 2000 and the lowest values were registered in 1996 and 1997. The number of coliform bacteria in nontreated waters showed a marked decrease in the last $3 \mathrm{yr}(2003,2004$, and 2005), which coincided with a change in the detection method. During this period, coliform bacteria concentration in treated waters was analyzed using the membrane filtration technique rather than fermentation in multiple tubes before 2002. However, as it was used lactose-fermentation-based methods for both MPN tubes, and membrane filtration techniques, and MPN cultures and colonies were always confirmed, it does not seem probable that the decrease of coliform bacteria is due to the changes in the detection method, and may therefore be real.

The seasonal pattern of microorganism concentration was variable during the study. In the first years (1996-1999), a peak in concentration was observed in summer; in 2000 a large peak was observed in the winter and in 2001 to 2005 the pattern of variation was even more irregular.

\section{Statistical Analysis Relevant to the Study}

A significant correlation (critical value at $1 \%$ is 0.081 for $n=$ 1000) was observed between fecal coliforms and SRCS $(r=$ $0.1225, n=17449)$ and between E. coli and C. perfringens ( $r=$ 0.1234, $n=4179)$. The correlation between $C$. perfringens and E. coli in treated water $(r=0.128732, n=1196, p=0.01)$ was higher than between SRCS and fecal coliforms $(r=0.10098, n$ $=9945, p=0.01$ ).

\section{Discussion}

During the last $2 \mathrm{yr}$ of the present study, a marked decrease of nonconform samples for microbiological parameters of drinking water is observed. Throughout this period, the fraction of conforming drinking waters is almost $70 \%$, a much higher value compared to that observed for the entire study period (55\%). The reduction of nonconform drinking water during 2004-2005 is due to specific safeguard actions that were taken by the local administration, such as the increase in the number of treated waters, but also to some extent, due to changes in current legislation (Decree 243/2001 [2001] transposed from 1998/83/EC Directive). Before the ruling of this legislation, the percentage of treated waters was $43 \%$ increasing to $71 \%$ after changes to the legislation. Considering the fraction of treated and nontreated waters separately, to eliminate the influence of the variation of the fraction of treated waters, it is observed that in the last $2 \mathrm{yr}$, the percentage of conforming waters increased against the tendency of previous years (79 against $67 \%$ during the two previous years for treated waters and 41 against $35 \%$ for nontreated waters). Considering the whole study period, the difference in relation to the last $2 \mathrm{yr}$ is lower but in 1999 and 2000 the percentage of nonconform waters is higher than the normal, probably due to the intense precipitation. In 1999 and 2000 the levels of accumulated precipitation were high, reaching in 1999 and 2000 levels of 877 and $1181 \mathrm{~mm}$, respectively (Almeida et al., 2007). The high level of precipitation may have contributed to the transport of terrestrial microorganisms by runoff and by resuspension of bottom sediments, which may have reached the water courses that supply the public network. 
One of the main alterations introduced by the new directive is the detection of $C$. perfringens (including spores) instead of examining for SRCS. This alteration contributed greatly toward the lowering of the requirements regarding water quality. Before the use of this directive, $18 \%$ of analyzed water samples show SRCS levels above limit. After this decree was put into practice, only $2 \%$ of the studied samples show $C$. perfringens results above PV. However, in the old directive the SRCS must be absent in 20 $\mathrm{mL}$, rather than in $100 \mathrm{~mL}$ as stated in the new directive for $C$. perfringens, but the fraction of nonconform waters are higher when the number of SRCS are used as an indicator, which means that these are more resistant to environmental factors and water treatment than $C$. perfringens and/or more abundant. On the other hand, the method of analysis of $C$. perfringens in the new directive requires enumeration of vegetative cells. This means that vegetative cells are included in the counts, but only the spores of $C$. perfringens are recognized as appropriate for testing the effectiveness of treatment used for drinking water and, consequently, to remove robust pathogens. This indicator can, in this way, underestimate the number of pathogenic bacteria in noneffectively treated waters, indicating that it is not a strong indicator of risk to public health.

Data from United Kingdom (UKWIR, 1996) show a low occurrence and low numbers of SRCS (1-3\% of samples). Other European studies (Hamilton, 1985; Seth and Edyvean, 2006) have reported regular occurrence of SRCS and their occurrence appears to be more related to growth of these bacteria in the distribution system associated with corrosion processes of pipes than with fecal pollution. Other studies (Araujo et al., 2004, Di Bari et al., 2007) have reported regular occurrence of $C$. perfringens. A regular incidence of $C$. perfringens spores in groundwater samples from public springs used for direct human consumption was detected in Spain (Araujo et al., 2004) where 40 of 51 groundwater samples analyzed (78.4\%) were found to be positive for $C$. perfringens spores. Di Bari et al.

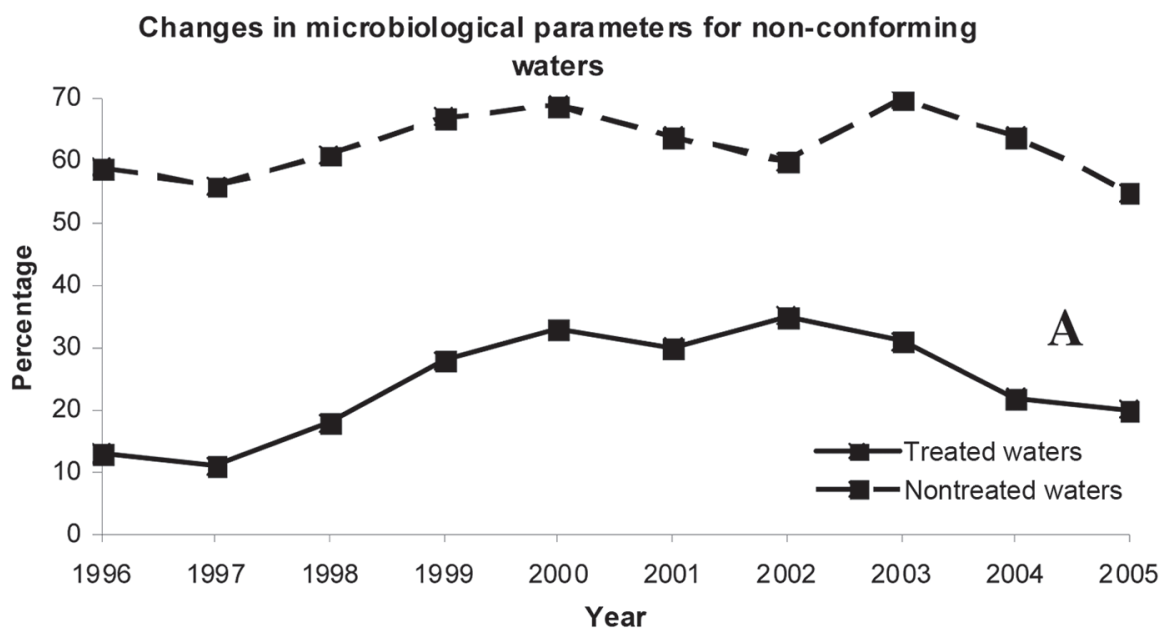

Changes in enterococci for non-conforming waters

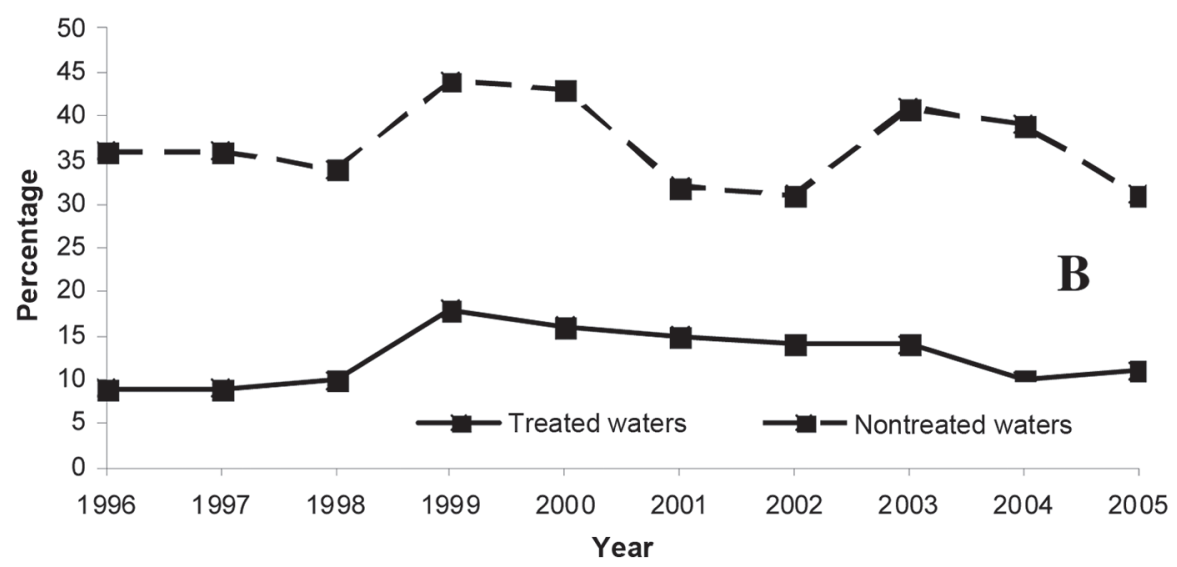

Changes in treated waters

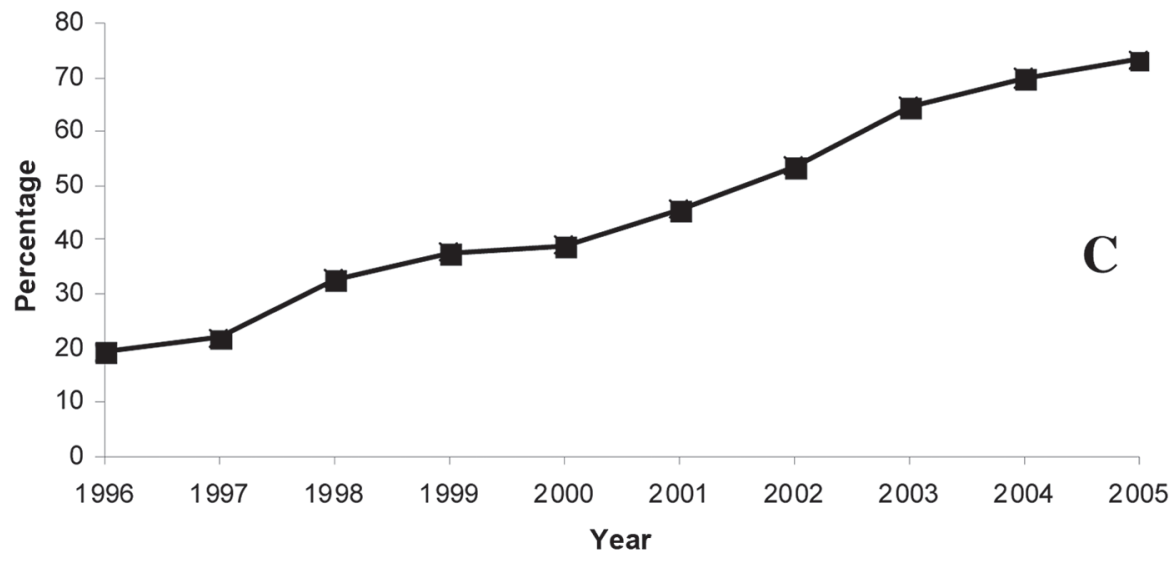

Fig. 2. (A and B) Microbiological classification of water for human consumption in District of Bragança, Portugal, by year, according to Government Decree 243/2001 (2001). (C) Percentage of treated waters during the study period.

(2007) in São Paulo, Brazil, reported the presence of C. perfringens in $16.5 \%$ (103 samples) of the drinkable water sources analyzed. Bonde (1963) suggested that all SRCS in waters are 
Heterotrophic Plate Counts $37^{\circ} \mathrm{C}$

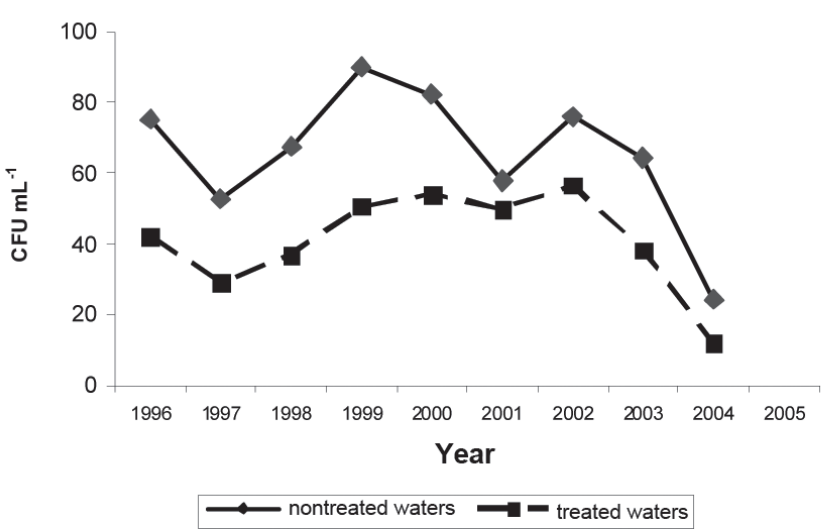

Enterococci

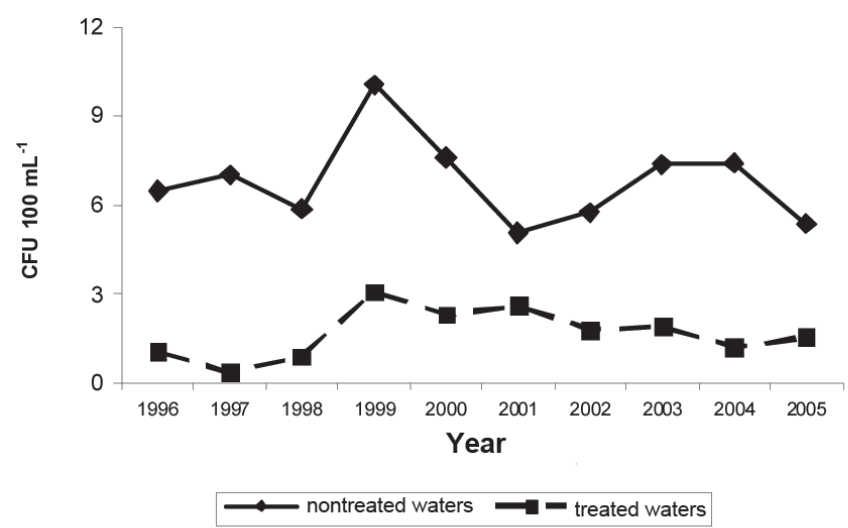

Total coliforms

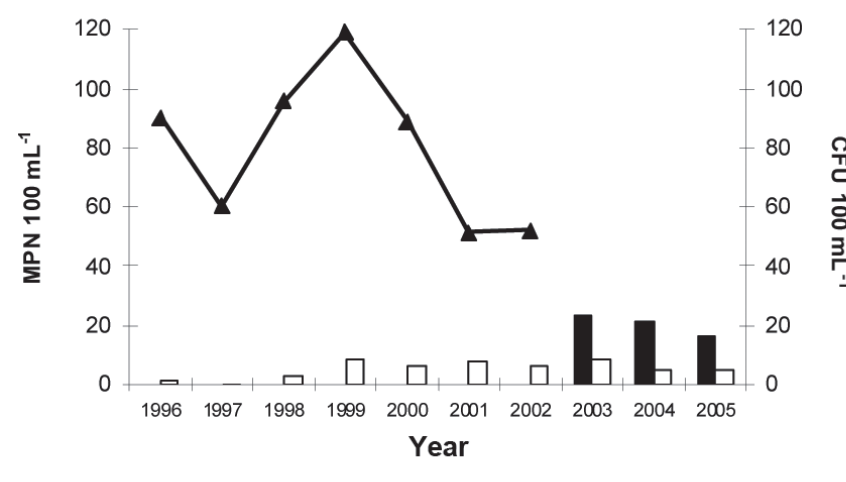

Fig. 3. Variation of the microorganism groups concentration between 1996 and 2005. The data until May 2004 refers to the concentration of sulfite-reducing clostridia spores and from May 2004 refers to the concentration of C. perfringens (NT, treated waters; T, treated waters). MF, membrane filtration; MPN, most probable number; SRCS, sulfite reduction clostria spores.

not indicators of fecal pollution and that $C$. perfringens is the appropriate indicator. On the other hand, according to Hoek (2008), C. perfringens should be kept, not to monitor water treatment, but as an indicator. He also advises that $C$. perfringens should not replace the SRCS as the water operators do not have sufficient experience with the use of $C$. perfringens.

Our study suggests that $C$. perfringens (including spores) and SRCS are good fecal indicators. A significant correlation
Heterotrophic Plate Counts $22^{\circ} \mathrm{C}$

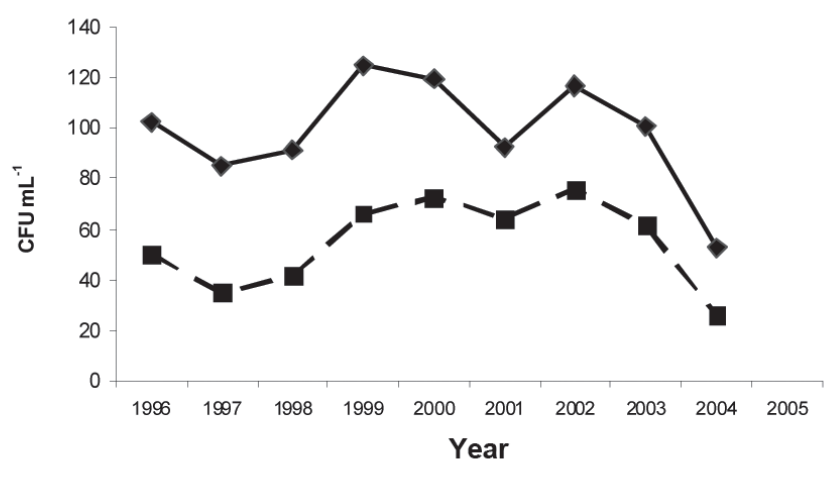

$\longrightarrow$ nontreated waters $\longrightarrow$ - treated waters

SRCS and C. perfringens

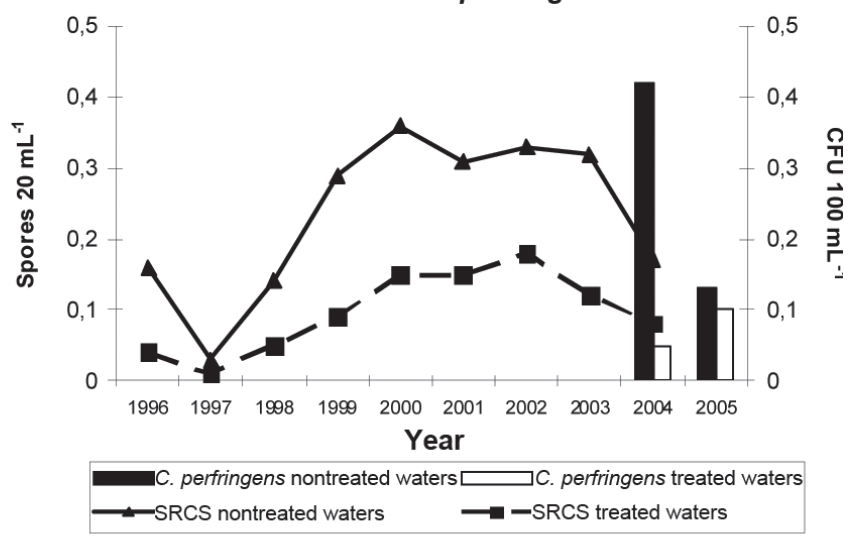

Fecal coliforms

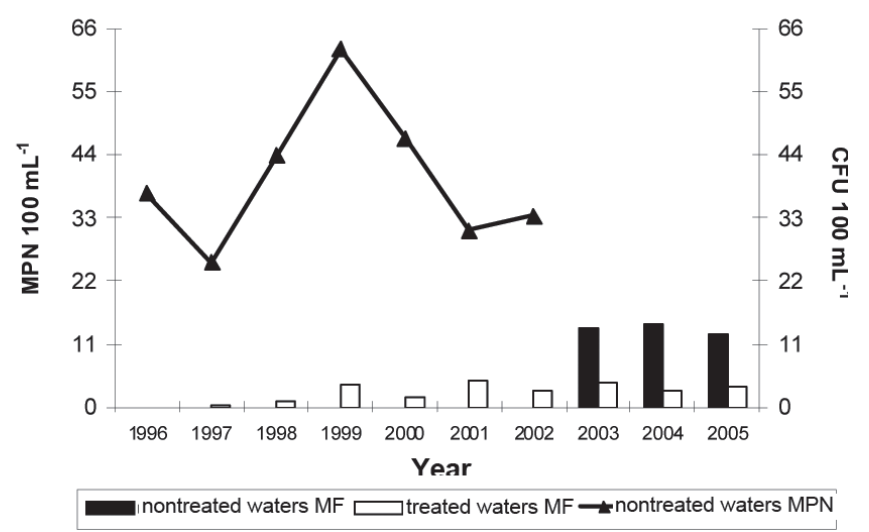

was observed between fecal coliforms, which are known to be constantly present in the human intestine in large numbers, and SRCS, and between E. coli, a fecal coliform, and C. perfringens. Our data suggest that sulfite-reducing clostridia spores are a better alternative than $C$. perfringens for monitoring water treatment. The percentage of samples with SRCS is $13 \%(n$ $=2276)$ in nontreated waters and $4.8 \%(n=842)$ in treated waters but the percentage of $C$. perfringens in nontreated and 
in treated waters is similar $(1 \%, n=40)$. The higher correlation between $C$. perfringens and $E$. coli relative to the correlation between SRCS and fecal coliforms, suggests also that SRCS is a better indicator of water treatment than $C$. perfringens. Vegetative cells of $C$. perfringens and of $E$. coli are easily destroyed through water treatment, but SRCS are more resistant than vegetative cells and a lower correlation between these indicators was observed. Vegetative cells of $C$. perfringens, as well as of fecal coliforms and of $E$. coli, present lower resistance than robust pathogens, such as Crytosporidium, to water treatment. For this reason, water treatment is better evaluated using SRCS. The occurrence of $C$. perfringens spores in treated water in the presence of $E$. coli as well as the incidence of SRCS in the presence of fecal coliforms suggest that water treatment is ineffective in removing the vegetative cells of microorganism indicators and, consequently, in eliminating waterborne pathogens. Consequently, 25\% of treated waters are classified as nonconform in this study.

Another alteration introduced by the Directive of 1998 is the drop in heterotrophic bacteria counts at $37^{\circ} \mathrm{C}$ because they are no longer regarded as indicators of fecal contamination (Reasoner, 1990; Rusin et al., 1997; Edberg and Allen, 2004). In this study, the heterotrophic bacteria counts at $37^{\circ} \mathrm{C}$ exceed more frequently the limit value, contributing to the classification of water samples as > RMV. As in the new EU Directive this parameter was dropped, the number of samples indicating conform increased. In fact, around $12 \%$ of the samples analyzed between 1996 and 2003 are classified as > RMV due to the high numbers of heterotrophic bacteria at $37^{\circ} \mathrm{C}(46.7 \%$ of the samples exceed the RMV) and at $22^{\circ} \mathrm{C}(27.8 \%$ of the samples exceed the RMV); these would be considered conform under the new Directive. Althought the heterotrophic plate counts at $22^{\circ} \mathrm{C}$, which are more abundant in drinking waters, is maintained in the new legislation, the limit for this parameter is higher than that for the heterotrophic plate counts at $37^{\circ} \mathrm{C}$ and, consequently, a lower percentage of waters exceed this value.

The alteration of legislation may modify the sanitary classification of drinking water, but not its microbiological quality. So, it is necessary to evaluate the true microbiological quality of the drinking water independently of the legislation. This can be achieved by removing a parameter that was detected only during part of the study period, such as heterotrophic plate counts, which are not real fecal indicators, or using only one parameter that was maintained during all the study period, in both legislations, as entecocci.

The classification of water in conform and nonconform during the study period does not reflect the quality in terms of heterotrophic plate counts since water with heterotrophic bacteria at 22 and $37^{\circ} \mathrm{C}$ above the recommended maximum value are considered in the old legislation as $>\mathrm{RMV}$, but are now classified as conform waters. The new classification does not consider the heterotrophic plate counts during the 1996-2003 period. Based in this classification, the apparent increase in quality of water is a consequence of an increase of treated waters, increasing from $19.3 \%$ in
1996 to $73.2 \%$ in 2005 , but not to the improvement of the treatment processes. The percentage of nonconforming for treated waters is higher in the period of 1999 to 2003 than in 1996-1998, decreasing again in 2004-2005. During the 1999-2003 period the percentage of nonconforming in treated waters is higher than in 1996-1998, indicating that the treatment was not improved during this period. In the last $2 \mathrm{yr}$, under the 1998/83 EC Directive, the percentage of nonconforming waters decrease. The percentage of nonconforming waters in the nontreated water is more constant throughout the whole study period, but the lowest values of nonconforming waters is reached in the last period (2004-2005), which confirms the effect of the changes in the legislation. Considering only the enterococci group, the same pattern of temporal variation is observed, but in the last $2 \mathrm{yr}$ the decrease in nonconforming samples in treated waters was lower $3.5 \%$ in relation to the two previous years) than that when all parameters are considered (12.0\% in relation to the two previous years). This confirms the effect of the increase of the percentage of treated waters, but also the importance of the changes introduced in the current legislation. Although low, the decrease of enterococci group in treated waters means that the water treatment in the last study period improved. This is also visible for total and fecal coliforms concentrations that clearly decrease in the last period.

In this study even though nontreated waters present a higher averaged microorganism concentrations than treated waters, a high percentage of treated waters is classified as nonconforming, throughout the study period. The high percentage of nonconforming in treated waters can be a result of an inefficient treatment, namely in the rural areas where drinking water is only disinfected. In the municipalities centers the water that supplies the public network is treated in Water Treatment Stations and, consequently, the problems are reduced compared to rural areas. Whereas in the municipalities $75.7 \%$ of the waters are classified as comforming, in rural areas, where water treatment consists mainly of chlorine disinfection alone, only $52.7 \%$ are conforming.

\section{Conclusions}

The presence of nonconforming samples of drinking water in the District of Bragança decreased throughout the study period, especially in the last $2 \mathrm{yr}$ due to an increase of the number of treated waters but also due to the alteration of the ruling legislation. However, in many rural municipalities, with disinfection as the only process of treatment, the percentage of undrinkable water remains high. Even considering only the treated waters the percentage of nonconforming samples is still high $(25 \%)$. The solution requires the evaluation of the factors that may be associated with this bad quality. In theses cases the water supply sources should be treated before the disinfection process. Municipalities, water distributors, laboratories, and Public Health entities together have to be prepared and capable to ensure quality water for human consumption, and by 
doing so, prevent many of the diseases which can be transmitted by contaminated waters. Only with an even more rigorous control, supported by hydrologic knowledge, will it be possible to adequately manage the available water thus providing the necessary water quality to the populations.

\section{References}

Almeida, A., A. Cunha, and M. Dias. 2007. Bacterial productivity distribution during a rainy year in an estuarine system. Microb. Ecol. 53:208-220.

Amaral, L., A. Filho, O. Júnior, F. Ferreira, and L. Barros. 2003. Drinking water in rural farms as a risk factor to human health. J. Public Health (Bangkok) 37:510-514.

Anderson, K., J. Whitlock, and V. Harwood. 2005. Persistence and differential survival of fecal indicator bacteria in subtropical waters and sediments. Appl. Environ. Microbiol. 71:3041-3048.

APHA. 1995. Standard methods for the examination of water and wastewater. 19th ed. American Public Health Assoc., Washington, DC.

Araujo, M., R. Sueiro, M. Gómez, and M. Garrido. 2004. Enumeration of Clostridium perfringens spores in groundwater samples: Comparison of six culture media. J. Microbiol. Methods 57:175-180.

Barrel, R., P. Hunter, and G. Nichols. 2000. Microbiological standards for water and their relationship to health risk. Commun. Dis. Public Health $3: 8-13$.

Bonde, G.J. 1963. Bacterial indicators of water pollution. Teknisk forlag. 2nd ed. Elsevier, Copenhagen.

Bove, F., Y. Shim, and P. Zeitz. 2002. Drinking water contaminants and adverse pregnancy outcomes: A review. Environ. Health Perspect. 110:61-74.

Chiller, T., C. Mendoza, B. Lopez, M. Alvarez, R. Hoekstra, B. Keswick, and S. Luby. 2006. Reducing diarrhea in Guatemalan children: Randomized controlled trial of flocculant-desinfectant for drinking-water. Bull. WHO 84:28-35.

Decree 74/1990. 1990. Journal Diário da Républica I Series A of 07/03/1990. p. 981-1024. Diário da Républica Portuguesa, Lisbon.

Decree 236/1998. 1998. Journal Diário da Républica, I Series A of 01/08/1998. p. 3676-3722. Diário da Républica Portuguesa, Lisbon.

Decree 243/2001. 2001. Journal Diário da Républica, I Series A of 05/09/2001. p. 5754-5765. Diário da Républica Portuguesa, Lisbon.

Di Bari, M., E. Hachich, A. Melo, and M. Sato. 2007. Aeromonas spp. and microbial indicators in raw drinking water sources. Braz. J. Microbiol. 38:516-521.

Edberg, S., and M. Allen. 2004. Virulence and risk from drinking water of heterotrophic plate count bacteria in human population groups. Int. J. Food Microbiol. 93:255-263.

Hamilton, W. 1985. Sulphate-reducing bacteria and anaerobic corrosion. Annu. Rev. Microbiol. 39:195-217.

Hellard, M., M. Sinclair, A. Forbes, and C. Fairley. 2001. A randomized, blinded, controlled trial investigating the gastroinstestinal health effects of drinking water quality. Environ. Health Perspect. 109:773-778.
Hoek, J.P. 2008. Revision of the Drinking water Directive 98/83/EC Stakeholder Forum-20 Feb. 2008. EUREAU Comments. EUREAU Position concerning the revision of the European Drinking Water Directive. Microbiological Parameters. EUREAU-1. WG Microbiological Quality. USP Headquarters, Rockville, MD.

International Organization for Standardization. 2000a. Water qualityDetection and enumeration of Escherichia coli and coliform bacteria in surface and waste water. Part 1: Membrane filtration method. ISO 9308-1:2000, Geneva.

International Organization for Standardization. 1986a. Water qualityDetection and enumeration of the spores of sulfite-reducing anaerobes (clostridia). Part 2: Membrane filtration method. ISO 6461-2:1986. ISO, Geneva.

International Organization for Standardization. 1986b. Water qualityDetection and enumeration of Clostridium perfringens. Part 2: Membrane filtration method. Revision of ISO 6461-2:1986. ISO, Geneva.

International Organization for Standardization. 1999. Water qualityEnumeration of culturable micro-organisms: Colony count by inoculation in a nutrient agar culture medium. ISO 6222:1999. ISO, Geneva.

International Organization for Standardization. 2000b. Water qualityDetection and enumeration of intestinal enterococci. Part 2: Membrane filtration method. ISO 7899-2:2000. ISO, Geneva.

Mendes, B., and J. Oliveira. 2004. Drinking-water quality (Qualidade da água para consumo humano). Lidel, 1 st ed. Lisbon.

Nieuwenhuijsen, M., M. Toledano, N. Eaton, J. Fawell, and P. Elliott. 1999. Chlorination disinfection byproducts in water and their association with adverse reproductive outcomes: A review. Occup. Environ. Med. 57:73-85.

Nogueira, G., C. Nakamura, M. Tognim, B. Filho, and B. Filho. 2003. Microbial quality of drinking water of urban and rural communities, Brazil. J. Public Health-UK 37:232-236.

Reasoner, D. 1990. Monitoring heterotrophic bacteria in potable water. p. 452-477. In G.A. McFeters (ed.) Drinking-water microbiology. Progress and recent developments. Springer-Verlag, New York.

Rusin, P., J. Rose, C. Haas, and C. Gerber. 1997. Risk assessment of bacterial pathogens in drinking water. Rev. Environ. Contam. Toxicol. 152:57-83.

Seth, A., and R. Edyvean. 2006. The function of sulfate-reducing bacteria in corrosion of potable water mains. Int. Biodeterior. Biodegrad. 58:108-111.

Strauss, B., W. King, A. Ley, and J. Hoey. 2001. A prospective study of rural drinking water quality and acute gastrointestinal illness. BMC Public Health $1: 8$.

Tominaga, M., and A. Midio. 1999. Humana exposure to trihalomethanes in drinking water. J. Public Health (Bangkok) 33:413-421.

UKWIR. 1996. Sulphite-reducing clostridia in drinking water supplies. Rep. DW-02/H2, p. 57. United Kingdom Water Industry Res., London.

World Health Organization. 2004a. Guidelines for drinking-water quality. 1:1-21. WHO, Geneva.

World Health Organization. 2004b. Guidelines for drinking-water quality. 12:296-461. WHO, Geneva. 